\title{
Experimental Study of the Composition and Structure of Granular Media in the Shear Bands Based on the HHC-Granular Model
}

\author{
Guang-jin Wang, ${ }^{1}$ Xiang-yun Kong, ${ }^{1}$ and Chun-he Yang ${ }^{2,3}$ \\ ${ }^{1}$ Kunming University of Science and Technology, Kunming 650093, China \\ ${ }^{2}$ Institute of Rock and Soil Mechanics, Chinese Academy of Sciences, Wuhan 430071, China \\ ${ }^{3}$ State Key Laboratory of Coal Mine Disaster Dynamics and Control, Chongqing University, Chongqing 400030, China
}

Correspondence should be addressed to Guang-jin Wang; wangguangjin2005@163.com

Received 9 June 2014; Accepted 25 July 2014; Published 31 August 2014

Academic Editor: Tifeng Jiao

Copyright (C) 2014 Guang-jin Wang et al. This is an open access article distributed under the Creative Commons Attribution License, which permits unrestricted use, distribution, and reproduction in any medium, provided the original work is properly cited.

\begin{abstract}
The researchers cannot control the composition and structure of coarse grained soil in the indoor experiment because the granular particles of different size have the characteristics of random distribution and no sorting. Therefore, on the basis of the laboratory tests with the coarse grained soil, the HHC-Granular model, which could simulate the no sorting and random distribution of different size particles in the coarse-grained soil, was developed by use of cellular automata method. Meanwhile, the triaxial numerical simulation experiments of coarse grained soil were finished with the different composition and structure soil, and the variation of shear strength was discussed. The results showed that the internal friction angle was likely to reduce with the increasing of gravel contents in the coarse-grained soil, but the mean internal friction angle significantly increased with the increment of gravel contents. It indicated that the gravel contents of shear bands were the major factor affecting the shear strength.
\end{abstract}

\section{Introduction}

The strength parameters of granular media are the main factor to affect the stability of dumping site. However, the reasonable strength parameters of granular media are hard to get. Jiang Jingshan's studies showed that the composition and fabric granular particle were the fundamental reasons that induced the macromechanical properties to be complex and led the macroscopic mechanical properties to show strong dispersion characteristics $[1,2]$. The influencing factors can be broadly divided into two kinds [3]. The first factor is the test site, load-applying manner, sample size, confining pressures, strain rate, drainage condition, the factors related with the material properties, and so forth. The second factor is human uncontrol. With the help of the traditional indoor tests method, the influence of artificial control factors on the strength of granular media had been thoroughly studied in order to obtain relatively reasonable values. Jiang et al. [4] discussed the effect of density and confining pressure on the mechanical properties of granular media and the influence on the stress-strain curves caused by confining pressure. Liu et al. [5] researched on the shear properties of rockfill under different stress paths conditions through large scale triaxial tests. Jiang and Zhao [6] and Dang et al. [7] studied the influence of shear rate on the shear strength of soil in triaxial tests. Li et al. [8] and Bagherzadeh-Khalkhali et al. [9] investigated the effect of the maximum particle size in coarse grained soil on the shear strength. Mao-tian et al. [10] accomplished the triaxial experiments of two series of loading on the sand by use of conventional triaxial compression test apparatus and studied the stress history and lithology, over consolidation ratio.

"Granular particle materials of different particle size is distributed randomly in space" is an obvious feature of granular media samples. The thesis [11, 12] indicated that the arrangement of mutual position and interparticle force of granular particle had important effect on the mechanical properties. Actually, many problems were related to the fabric 


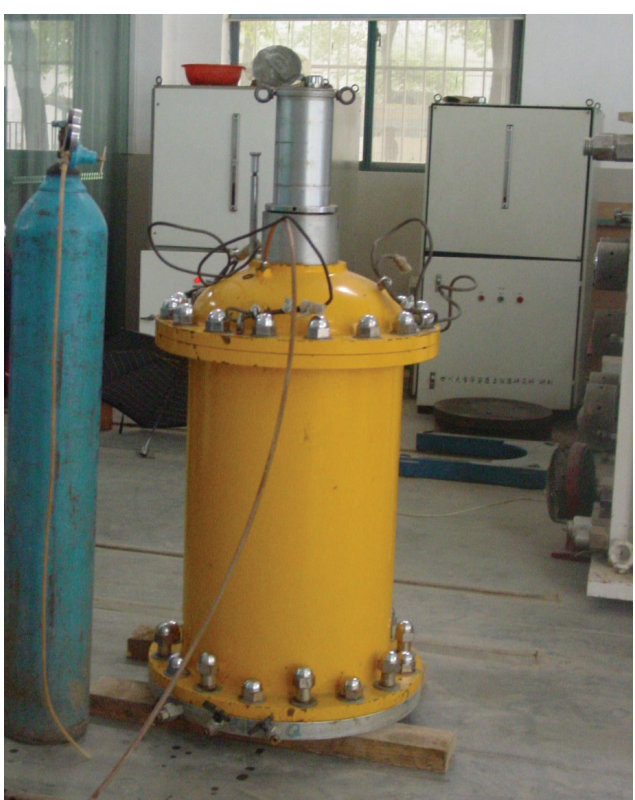

Figure 1: The triaxial test of granular media.

of granular media. The granular media fabric of sample was uncontrolled in the indoor tests and the experiments would cost lots of time and labor. So it was, by far, that very few people studied this field. In fact, by reason of the random distribution of the different granular particle during the tests, the fabric of granular samples might be quite different. Even if the tests personnel, experimental method and material, experimental grading and density, and experimental apparatus are identical, the indoor tests results also are different. Therefore, using a few indoor tests results to stand for the strength parameters was unreasonable and such mechanical parameters had no representativeness. So it is necessary to introduce into the numerical simulation triaxial tests for coarse-grained soil.

\section{HHC-Granular Model}

2.1. Laboratory Triaxial Experiment. At first, a group of indoor triaxial tests of granular media was carried out, and the experimental image was shown in Figure 1. According to the classification and naming of granular media [13], the granular media of laboratory experiment was described as the gravel $(0.005 \sim 0.06 \mathrm{~m})$, sand $(0.0001 \sim 0.005 \mathrm{~m})$, and soil $(<0.0001 \mathrm{~m})$. The particle size range was given in Table 1 . The tests apparatus is the stress-control triaxial compression which was developed by Sichuan University. The maximum particle selected $0.06 \mathrm{~m}$ and its shear rate was $5 * 10^{-7} \mathrm{~m} \cdot \mathrm{s}^{-1}$. The tests confining pressure selected $200 \mathrm{kPa}, 400 \mathrm{kPa}$, $800 \mathrm{kPa}$, and $1600 \mathrm{kPa}$ and the experiment was shut down in axial strain $15 \%$.

In keeping with the laboratory experimental conditions as soon as possible, the granular media sample of numerical simulation test was considered to consist of three kinds of similar particle materials that were the coarse gravel,

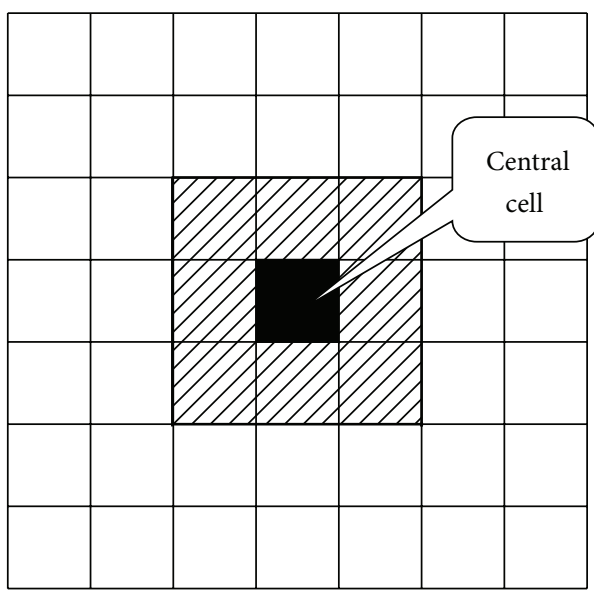

FIGURE 2: Schematic diagram of cellular, cellular space, and neighbor.

medium-grained sand, and fine-grained soil. Therefore, the cellular automata was employed to generate randomly the homogeneous hybrid composite in order to prepare the samples with different initial fabric of grain.

2.2. HHC-Granular Model. By use of the horizontal and vertical lines of equal intervals, two-dimensional space was divided into the cellular space consisted of square, and each square was cellular. The cellular spatial grid was $50 \times 100$. The eight neighbors' Moore model was shown in Figure 2; when the black cellular was the central, the eight cellulars with the diagonal line are its neighbor.

There are three kinds of cellular states representing three different materials, 2: gravel; 1: sand; 0: Soil. In the procedure, we used different colors to indicate the cellular of different states and took the periodic boundary conditions as the boundary condition.

Cellular automata has discrete features on the time and space and can make synchronized calculation, and its cellular state changed with the change in time and space. In the cellular space, at first, several nucleation-points appeared randomly; then the cellular gradually developed according to probability around the nucleation-point. The more the cellulars around the nucleation-point, the greater the growing probability, and when there were no cellulars around the nucleation-point, the growth probability was zero. As the ambient cellulars were the same kind of cellular, the growth probability was $100 \%$. The evolution would be continued until the material met the required content percentage.

The cellular was not the simultaneous evolution but the ergodic evolution in the cellular space. It was distinct from previous cellular automaton that cellular evolution depended on not only back state of neighbor cellular, but also current state of neighbor cellular evolved,

2.3. Simulating Results. Figure 3 was the interface of HHCGranular model with three granular medias (gravel, sand, and soil). The granular media samples which were generated by HHC-Granular model could characterize the granular 


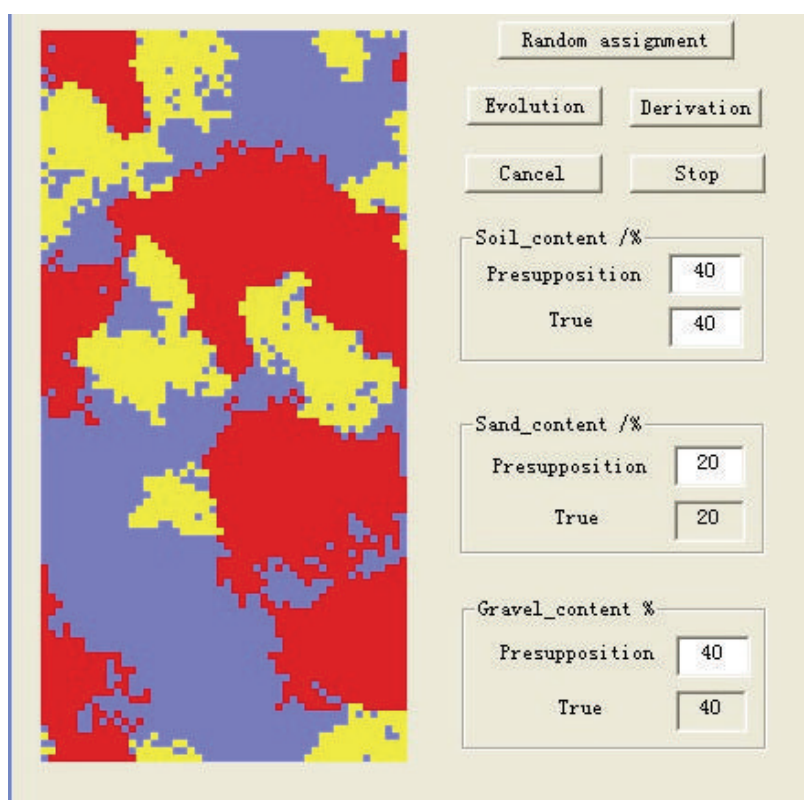

FIGURE 3: HHC-Granular model interface and generated granular sample.

inhomogeneous and random distribution from the graph. This model could define the different contents of soil, sand, and gravel and randomly generate samples with the different fabric in the same particle size grading so as to prepare the requiring granular media samples. The HHC-Granular model was maneuverable. Introducing the granular media sample which was simulated by the HHC-Granular model into the FLAC ${ }^{3 \mathrm{D}}$, we could realize that the distribution of each particle size was identical.

\section{Triaxial Numerical Simulation Tests}

3.1. Numerical Calculating Model. In the riaxial numerical calculating model of granular media, the specimen dimensions was $0.5 \mathrm{~m} \times 0.01 \mathrm{~m} \times 1 \mathrm{~m}$, the normal constraint was applied on the $X=0 \mathrm{~m}$ and $X=0.5 \mathrm{~m}$ planes and the normal stress was applied on the $Y=0 \mathrm{~m}$ and $Y=0.01 \mathrm{~m}$ planes; the $Z=0 \mathrm{~m}$ plane was applied on the normal constraint and the $Z=1 \mathrm{~m}$ plane was applied on the loading rate.

\subsection{Material Parameters and Experimental Schemes for} Numerical Simulation Tests of Granular Media. In keeping with indoor tests conditions, this simulation tests took the indoor triaxial tests of granular media as a reference. The loading rate is $5 * 10^{-7} \mathrm{~m} \cdot \mathrm{s}^{-1}$ and the normal stress adopted $200 \mathrm{kPa}, 400 \mathrm{kPa}, 800 \mathrm{kPa}$, and $1600 \mathrm{kPa}$. The material parameters of gravel, sand, and soil were acquired based on the parameters of indoor tests and the simulating test using the Mohr-Coulomb model; the simulating tests' material parameters were shown in Table 1.

According to the project names and classifications with the granular media [13], the granular media was divided into five categories to follow the contents of greater than $5 \mathrm{~mm}$ : that was sand of soil, sandy soil of gravel, gravelly soil of sand, sandy gravel of soil, and sandy gravel of rubble. The classification is in Table 2.

To study the reasonable strength parameters with different granular media, the paper selected the HHC-Granular model to prepare the five different granular media samples and the simulating five samples of granular media were shown in Figure 4. Meanwhile, each granular media prepared 40 groups of samples with different fabric to do the triaxial simulation tests. The strength parameter $\varphi$ of different initial fabric of grain was acquired.

\section{Test Results}

4.1. Numerical Simulation. Figure 5 contrasted the stressstrain curve of laboratory experiment with that of triaxial numerical simulation test in the experimental schemes II. The simulation curves were wave type from the chart, while the indoor tests were not so obvious, because the shear bands avoided the coarse particle and always had some coarse particles in the simulation test until the failure surface was formed. In the numerical simulation tests process, the simulation curve could form a wave rising trend line, while the indoor triaxial tests were completed to express mainly particle displacement and its curves performed for the smooth curve. Overall, the stress-strain curves between the simulation tests and the indoor triaxial tests were uniform largely, which indicated that the triaxial numerical simulation tests, which combined the FLAC ${ }^{3 \mathrm{D}}$ with the HHC-Granular model, were feasible.

Figure 6 was the different fabric charts of FS.G, and Figure 7 was the corresponding contours of shear-strain rate. Combining Figure 6 with Figure 7, we could see that the gravel of Figure 6(a) appeared primarily near the shear bands and its internal friction angle was $29.69^{\circ}$. The sand accounted for a larger proportion near shear bands in Figure 6(b) and its internal friction angle was lower than that of Figure 6(a). The internal friction angle of Figure 6(c) was $26.84^{\circ}$, and the contents of soil in the shear bands was relatively higher. The results showed that when there was more gravel in the nearby shear bands, the internal friction angle values were higher, and the shear strength was relatively lower as a lot of soil lied in the nearby shear bands. Thus the shear strength of samples had to do with the particle distribution in the vicinity of shear bands.

Figure 7 showed that, as the influence of coarse particles on the tests, the shear failure plane was not regular shear plane, but some curved surface. However, the tendency of curve surface showed that the curves of shear bands appeared as a single shear bands or " $X$ " shear bands. Therefore, in order to quantify the impact of coarse particles in the shear bands on the shear strength, this adopted the " $X$ " shear bands to analyze the effect of gravel contents within the shear bands on the shear strength of sample.

4.2. Shear Bands and Inclination Angle of Shear Bands. The paper generated the total cell $N$ (the HHC-Granular model unit numbers) and displayed the grid ID numbers of FLAC ${ }^{3 \mathrm{D}}$ 


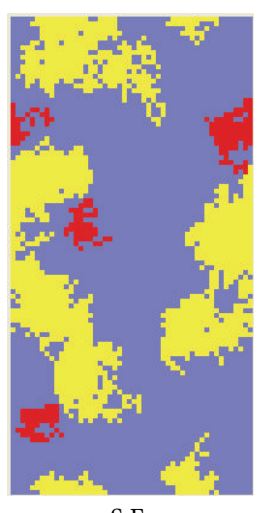

S.F

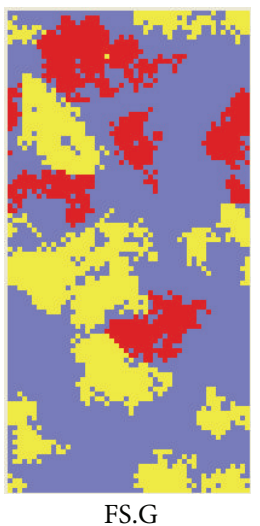

FS.G

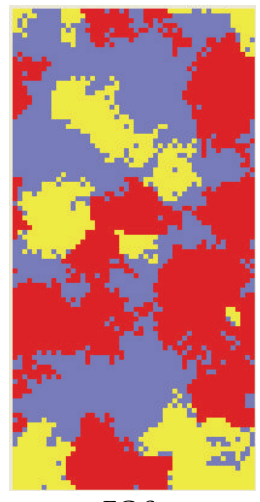

FG.S

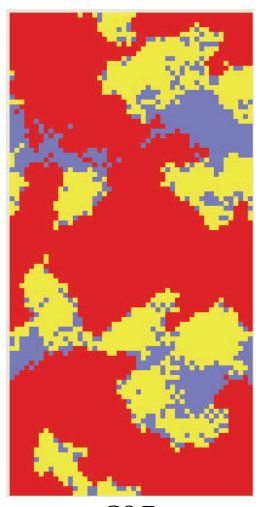

GS.F

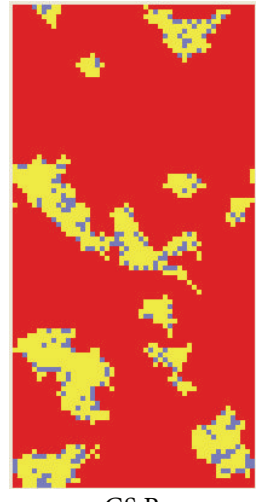

GS.R

Soil

- Sand

Gravel

FIGURE 4: HHC-Granular model generated granular media samples.

TABLE 1: Material parameters for numerical simulation tests of granular media.

\begin{tabular}{lcccccccc}
\hline Names & $\begin{array}{c}\text { Range of } \\
\text { particle size }(\mathrm{m})\end{array}$ & $\begin{array}{c}\text { Density } \\
\left(\mathrm{kg} \cdot \mathrm{m}^{-3}\right)\end{array}$ & $\begin{array}{c}\text { Cohesion } \\
\times 10^{3}(\mathrm{~Pa})\end{array}$ & $\begin{array}{c}\text { Internal } \\
\text { frictional angle } \\
\left({ }^{\circ}\right)\end{array}$ & $\begin{array}{c}\text { Dilation } \\
\text { angle }\left(^{\circ}\right)\end{array}$ & $\begin{array}{c}\text { Bulk modulus } \\
\times 10^{9}(\mathrm{~Pa})\end{array}$ & $\begin{array}{c}\text { Shear modulus } \\
\times 10^{9}(\mathrm{~Pa})\end{array}$ & $\begin{array}{c}\text { Tensile } \\
\text { strength } \times 10^{6} \\
(\mathrm{~Pa})\end{array}$ \\
\hline Soil (F) & $<0.0001$ & 2150 & 61 & 27 & 8 & 0.07 & 0.03 & 0.05 \\
Sand (S) & $0.0001 \sim 0.005$ & 2300 & 75 & 32 & 10 & 2.5 & 1 & 0.35 \\
Gravel (G) & $0.005 \sim 0.06$ & 2600 & 132 & 46 & 13 & 23 & 10 & 1.0 \\
\hline
\end{tabular}

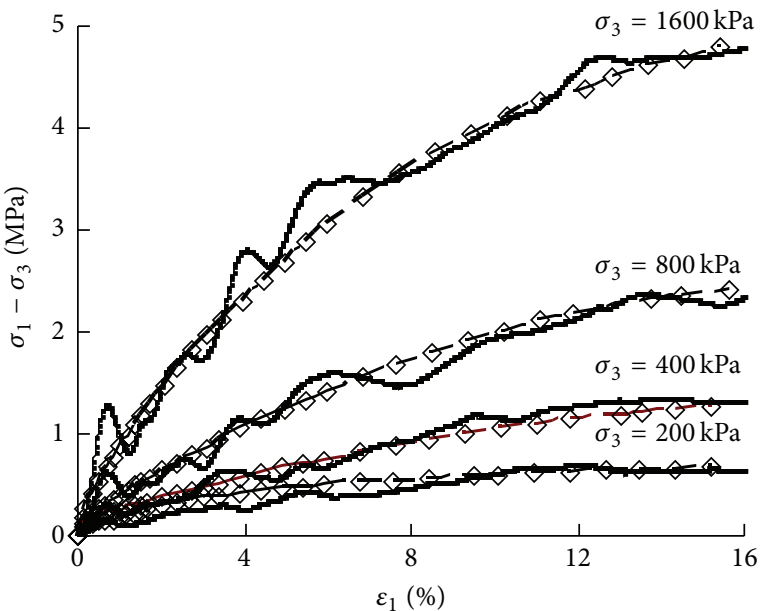

$\rightarrow$ Simulative curves

$-\diamond-$ Experimental curves

FIGURE 5: Stress-strain curves of between simulation tests and indoor tests.

in the triaxial simulation tests to obtain the gravel contents of shear bands. And then the producing grid image was induced into AutoCAD and shear bands were set. The schematic diagram was shown in Figure 8 . The units $n$ of gravel in the shear bands were acquired by comparing with the unit number generated by the HHC-Granular model. Finally, we could calculate the gravel contents of shear bands:

$$
p_{5}=\left(\frac{n}{N}\right) \times 100 \%
$$

where $P_{5}$ is gravel contents of shear bands, $n$ is total units of gravel in the shear bands, and $N$ is total units $n$ of sample.

According to Finno et al. [14], the inclination angle and thickness of shear bands with Sandy soil of gravel were taken as $\psi=65^{\circ}$ and $D=0.045 \mathrm{~m}$, with which we obtained the gravel contents of FS.G with 60 groups different fabric in the shear bands. The relationship between gravel contents in shear bands and internal friction angle of FS.G was shown in Figure 9.

Figure 9 showed that the internal friction angle is increscent with the increasing of the gravel contents with the shear bands, and there was a linear relation between the gravel contents of shear bands and the internal friction angle. It indicated that the gravel contents of shear bands were the major factor affecting the shear strength.

The range value of internal friction angles $(\varphi)$ with the five categories granular media, which were acquired through the triaxial simulation tests, was shown in Figure 10. The internal friction angle $(\varphi)$ was not always increment with the increase of the sample gravel contents from the chart. The higher $\varphi$ of gravel contents $4 \%$ is greater than the lower $\varphi$ as the gravel contents are $15 \%$. When the gravel contents are $40 \%$, the lower $\varphi$ is less than the higher $\varphi$ of gravel contents $15 \%$. Similarly, 

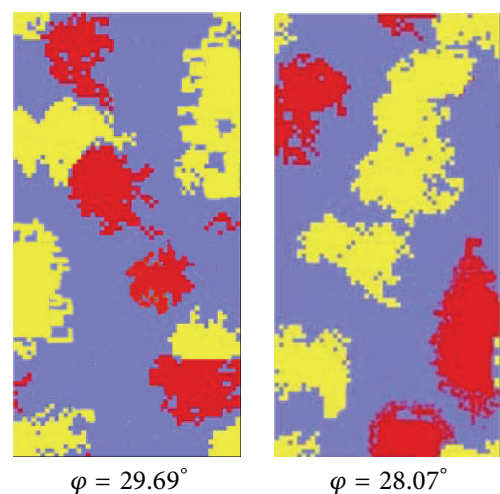

$\varphi=28.07^{\circ}$

Soil
Sand
Gravel

Gravel

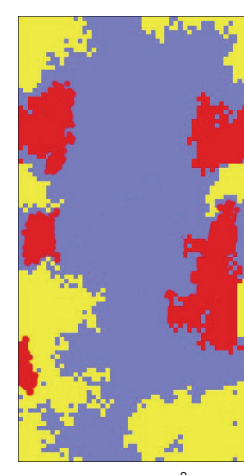

$\varphi=26.84^{\circ}$

Soil

Sand

- Gravel

(a)

(b)

(c)

FIGURE 6: HHC-Granular model generated different initial fabric of grain of FS.G.

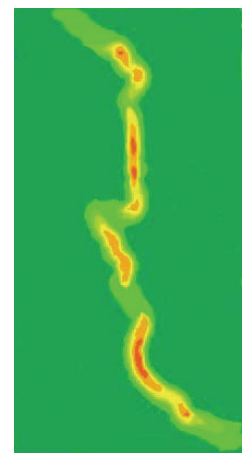

$\varphi=29.69^{\circ}$

(a)

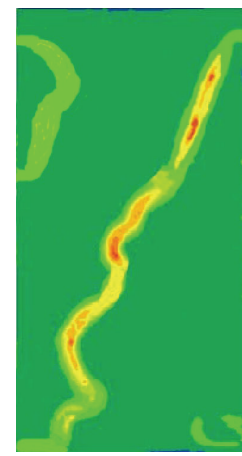

$\varphi=28.07^{\circ}$

(b)

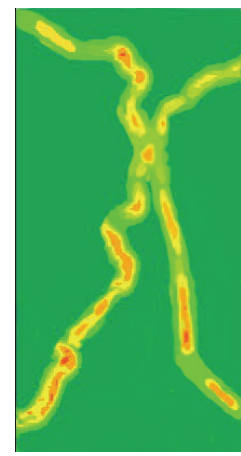

$\varphi=26.84^{\circ}$

(c)

FIGURE 7: Contours of shear-strain rate indicating shear bands at different fabric.

the higher $\varphi$, as the gravel content is $40 \%$, was greater than the lower $\varphi$ when the gravel content is equal to $60 \%$. Actually, the phenomenon, which the internal friction angle of higher gravel contents sample is less than that of lower sample gravel contents, can also appear in the indoor tests. It is caused by the different fabric of sample. Although the sample gravel contents were higher, due to the lower sample gravel contents in the shear bands, the internal friction angle may decrease. The analysis showed that the influence factors to the strength parameters of granular media were not always the sample gravel contents, but the gravel contents of shear bands in some situations.

Figure 11 expressed the relationship between the average internal friction angle that was got through the triaxial simulation test and the samples gravel contents with sand of soil, sandy soil of gravel, gravelly soil of sand, sandy gravel of soil, and sandy gravel of rubble. Figure 11 showed that although the $\varphi$ of higher gravel contents was less than that of lower gravel contents, the average internal friction angle of different gravel contents obviously increased with the increment of sample gravel contents and the relationship between $\bar{\varphi}$ and sample gravel contents could be expressed by exponential relation which could provide reference for the selection of mechanical parameters.

\section{Conclusions}

Generally, acquiring the mechanical properties of similar particle size with the granular media is relatively easy in the indoor tests. However, the granular media has characteristics of obvious heterogeneity and randomness, which caused the reasonable mechanical parameters to be obtained difficultly through a few indoor tests. The paper, combining HHCGranular model with FLAC ${ }^{3 \mathrm{D}}$, tentatively discussed the influence of gravel contents on the shear strength of granular media. The results showed that the stress-strain curves of numerical simulation tests were consistent with that of indoor tests with granular media. With the increase of gravel contents within the shear bands, the internal friction angle was increscent and the relationship expressed linear relation, 
TABLE 2: Classification and gradation schemes of simulation tests of granular media.

\begin{tabular}{|c|c|c|c|c|c|c|c|}
\hline \multirow{2}{*}{$\begin{array}{l}\text { Test } \\
\text { schemes }\end{array}$} & \multirow[t]{2}{*}{ Project names } & \multirow{2}{*}{$\begin{array}{l}\text { Symbols of } \\
\text { classification }\end{array}$} & \multicolumn{2}{|c|}{$\begin{array}{l}\text { Contents of different grain size } \\
\text { groups of classification }\end{array}$} & \multicolumn{3}{|c|}{ Simulated true values of different grain sizes } \\
\hline & & & Gravel (\%) & Soil (\%) & Gravel (\%) & Sand $(\%)$ & Soil (\%) \\
\hline I & Sand of soil & S.F & $<5$ & $\geq 10 \%$ & $4.0 \%$ & $30.0 \%$ & $66.0 \%$ \\
\hline II & Sandy soil of gravel & FS.G & $<30$ & $>10 \%$ & $15.0 \%$ & $25.0 \%$ & $60.0 \%$ \\
\hline III & $\begin{array}{c}\text { Gravelly soil of } \\
\text { sand }\end{array}$ & FG.S & $30-50$ & $>10 \%$ & $40.0 \%$ & $20.0 \%$ & $40.0 \%$ \\
\hline IV & Sandy gravel of soil & GS.F & $50-70$ & $>10 \%$ & $60.0 \%$ & $25.0 \%$ & $15.0 \%$ \\
\hline $\mathrm{V}$ & $\begin{array}{c}\text { Sandy gravel of } \\
\text { rubble }\end{array}$ & GS.R & $>70$ & $<5 \%$ & $80.0 \%$ & $16.0 \%$ & $4.0 \%$ \\
\hline
\end{tabular}

\begin{tabular}{|c|c|c|c|c|c|c|c|c|c|}
\hline 191 & 192 & 193 & 194 & 195 & 196 & 197 & 198 & 199 & 200 \\
\hline 181 & 182 & 183 & 184 & 185 & 186 & 187 & 188 & 189 & 190 \\
\hline 171 & 172 & 173 & 174 & 175 & 176 & 177 & 178 & 179 & 180 \\
\hline 161 & 162 & 163 & 164 & 165 & 166 & 167 & 168 & 169 & $1 / 10$ \\
\hline 151 & 152 & 153 & 554 & 155 & 156 & 15 & 158 & 159 & 160 \\
\hline 141 & 142 & 143 & 144 & 145 & 146 & 147 & 548 & 149 & 150 \\
\hline 131 & 132 & 133 & 134 & 35 & 136 & 137 & 138 & 139 & 140 \\
\hline 121 & 122 & 123 & 124 & 125 & 126 & 127 & 128 & 129 & 130 \\
\hline 111 & 112 & 113 & 114 & 115 & 116 & 117 & 118 & 119 & 120 \\
\hline 101 & 102 & 103 & 104 & 105 & 106 & 107 & 108 & 109 & 110 \\
\hline 91 & 92 & 93 & 94 & 95 & 96 & 97 & 98 & 99 & 100 \\
\hline 81 & 82 & 83 & 84 & 85 & 86 & 87 & 88 & 89 & 90 \\
\hline 71 & 72 & 73 & 74 & 75 & 76 & 77 & 78 & 79 & 80 \\
\hline 61 & 62 & 63 & 64 & 65 & 66 & 67 & 68 & 69 & 70 \\
\hline 51 & 52 & 53 & 54 & 55 & 56 & 57 & 858 & 59 & 60 \\
\hline 41 & 42 & 43 & 44 & 45 & 46 & 47 & 48 & 49 & 50 \\
\hline 31 & 32 & 33 & 34 & 35 & 36 & 37 & 38 & 39 & 40 \\
\hline 21 & 22 & 25 & 24 & 25 & 26 & 27 & 89 & 29 & 30 \\
\hline 11 & 12 & 13 & 14 & 15 & 16 & 17 & 18 & 19 & 20 \\
\hline 1 & 2 & $\Psi 3$ & 4 & 5 & 6 & 7 & 8 & 9 & 10 \\
\hline
\end{tabular}

$D$ : thickness of shear bands

$\Psi$ : inclination angle of shear bands

FIGURE 8: Schematic diagram of shear bands.

and the internal friction angle might decrease when the gravel contents increased. However, the average internal friction angle of different gravel contents is increasing obviously with the increase of sample gravel contents.

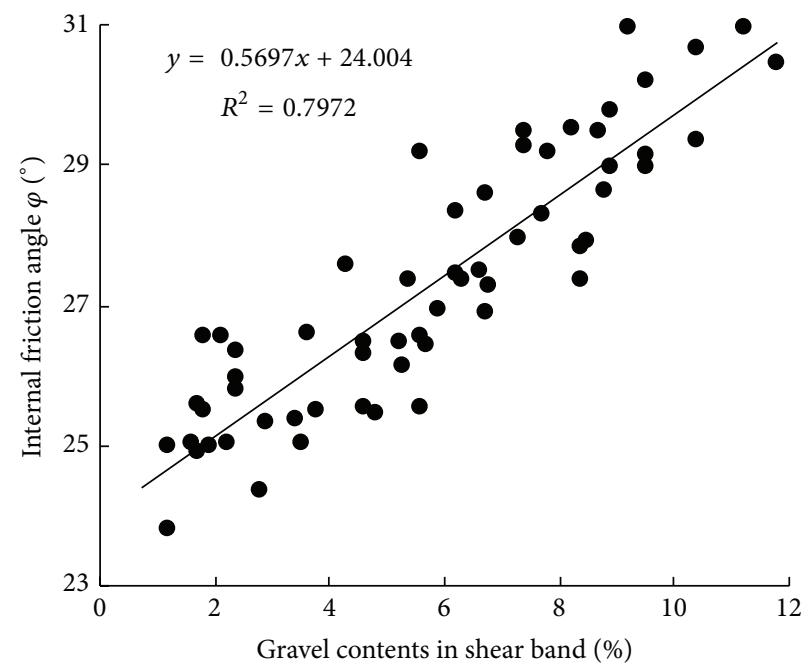

FIGURE 9: Relationship between gravel contents in shear bands and internal friction angle.

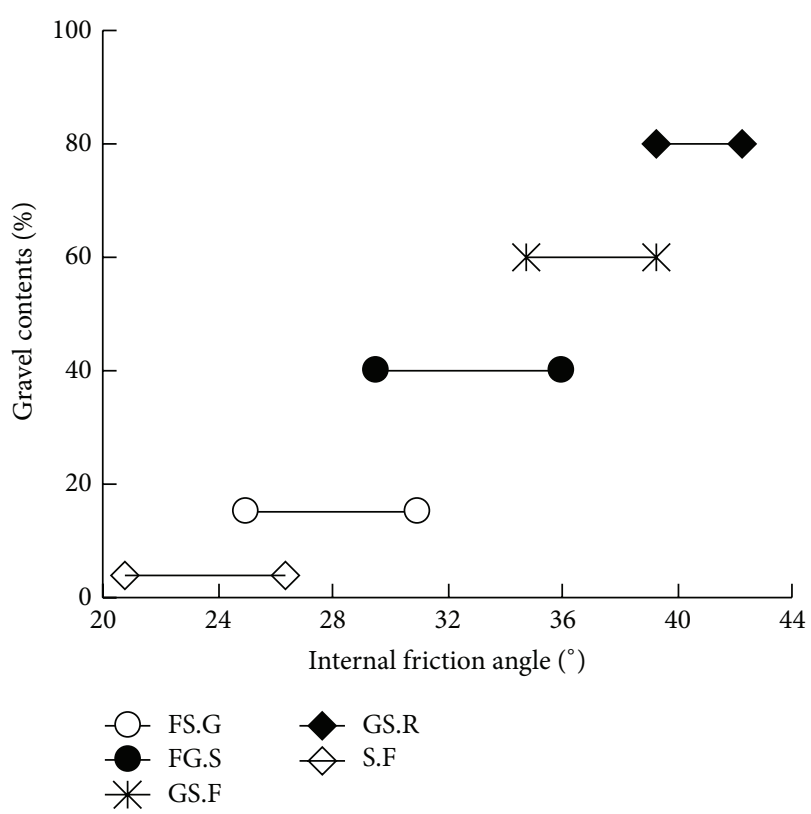

FIGURE 10: Range of internal friction angle at different granular media. 


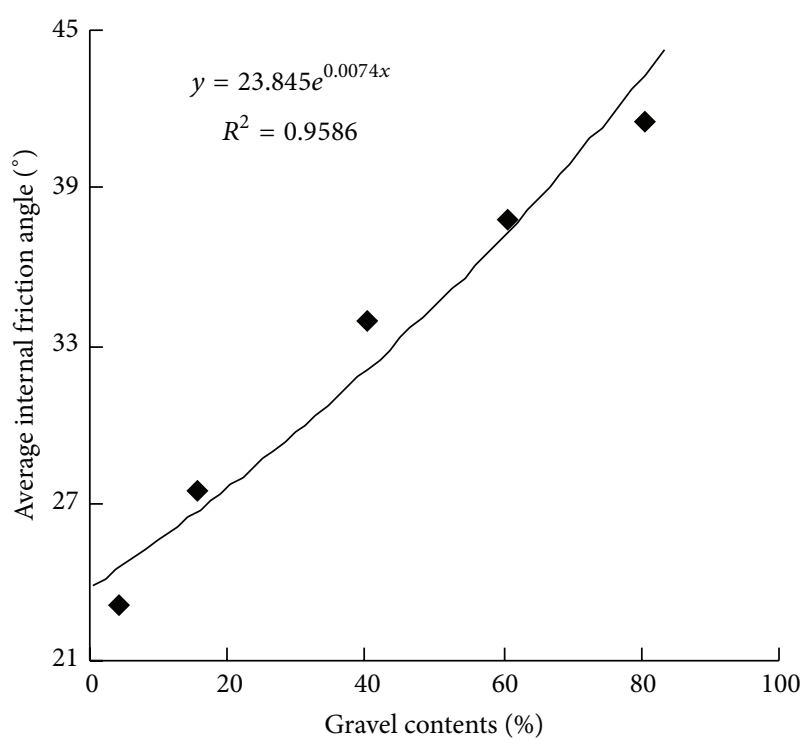

FIGURE 11: Relationship between $\bar{\varphi}$ and gravel contents of samples.

\section{Conflict of Interests}

The authors declare that there is no conflict of interests regarding the publication of this paper.

\section{Acknowledgments}

This research is supported by the project supported by the National Natural Science Foundation of China (no.51234004), the Open Projects with the State Key Laboratory of Coal Mine Disaster Dynamics and Control (Chongqing University) (no. 2011DA105287-KF201307), the School-Enterprise Funds with the Jinchuan Group co., Ltd.(no. KKZ4201221008), the Yunnan Provincial Fund project (no. KKSY201221070), and the Discipline Direction Team (no. KKZ4201414078312).

\section{References}

[1] J. Jiang, Z. Cheng, H. Liu, and H. Ding, "Fabric analysis of twodimensional tests for coarse-grained soils," Chinese Journal of Geotechnical Engineering, vol. 31, no. 5, pp. 811-816, 2009.

[2] C. Zhanlin, D. Hongshun, and W. Liangping, "Experimental study on mechanical behaviour of granular material," Chinese Journal of Geotechnical Engineering, vol. 29, no. 8, pp. 1152-1158, 2007.

[3] L. I. Nenghui, Recent Technolohy for High Concrete Face Rockfill Dams, China Water Power Press, Beijing, China, 2007.

[4] J.-S. Jiang, H.-L. Liu, and Z.-L. Cheng, "Influences of density and confining pressure on mechanical properties for coarsegrained soils," Journal of Yangtze River Scientific Research Institute, vol. 26, no. 8, pp. 46-50, 2009.

[5] M. Liu, Y. Gao, and H. Liu, "Study on shear behaviors of rockfill in large-scale triaxial tests under different stress paths," Chinese Journal of Rock Mechanics and Engineering, vol. 27, no. 1, pp. 176186, 2008.
[6] H.-W. Jiang and X.-H. Zhao, "Analysis of the shearing rate effecton anisotropic undrained strength of clays," Journal of Tong Ji University, vol. 25, no. 4, pp. 390-395, 1997.

[7] J. Dang, C. Jiang, and Z. Ji, "Effects of shear rate on mechanical behavior of structured loess," Chinese Journal of Underground Space and Engineering, vol. 5, no. 3, pp. 459-463, 2009.

[8] C. Li, C.-R. He, C. Wang et al., "Study of scale effect of largescale triaxial test of coarse-grained meterials," Rock and Soil Mechanics, vol. 29, supplement, pp. 563-566, 2008.

[9] A. Bagherzadeh-Khalkhali and A. A. Mirghasemi, "Numerical and experimental direct shear tests for coarse-grained soils," Particuology, vol. 7, no. 1, pp. 83-91, 2009.

[10] L. Mao-tian, L. Gao, and Y. Qing, "Review of geotechnical earthquake engineering and some latest progress in the soil dynamics," in Proceedings of the 5th National Soil Dynamics Conference Proceedings, Dalian University of Science and Technology Press, Dalian, China, 1998.

[11] J.-S. Jiang, Z.-L. Chen, and X.-L. Jiang, "Two dimensional model test for coarsegrained soil," Journal of Yangtze River Scientific Research Institute, vol. 25, no. 2, pp. 38-41, 2008.

[12] W. Xu, R. Hu, Z. Q. Yue, R. Zhang, and G. Wang, "Research on relationship between rock block proportion and shear strength of soil-rock mixtures based on digital image analysis and large direct shear test," Chinese Journal of Rock Mechanics and Engineering, vol. 27, no. 5, pp. 996-1007, 2008.

[13] Q. Guo, Engineering Properties and Applieation of Coarsegrained Soil, Yellow River Water Conservancy Press, Zhengzho, China, 1999.

[14] R. J. Finno, W. W. Harris, M. A. Mooney, and G. Viggiani, "Shear bands in plane strain compression of loose sand," Geotechnique, vol. 47, no. 1, pp. 149-165, 1997. 

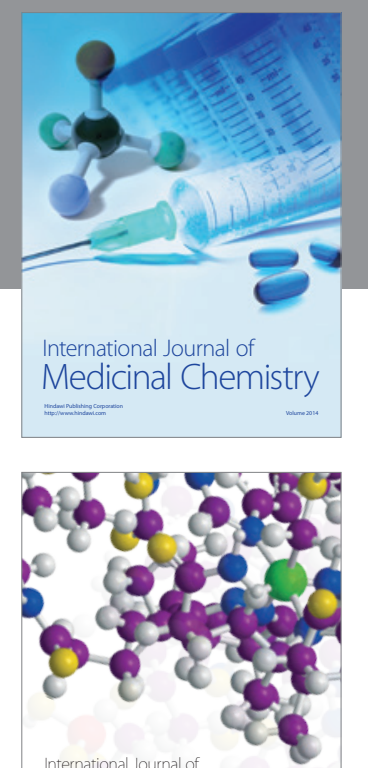

\section{Carbohydrate} Chemistry

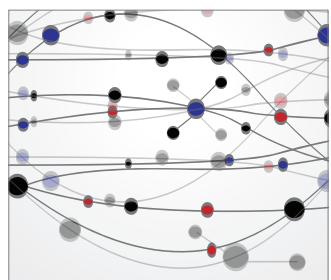

The Scientific World Journal
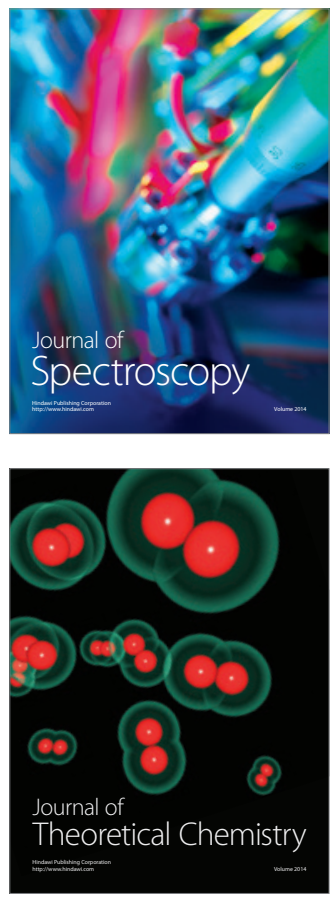
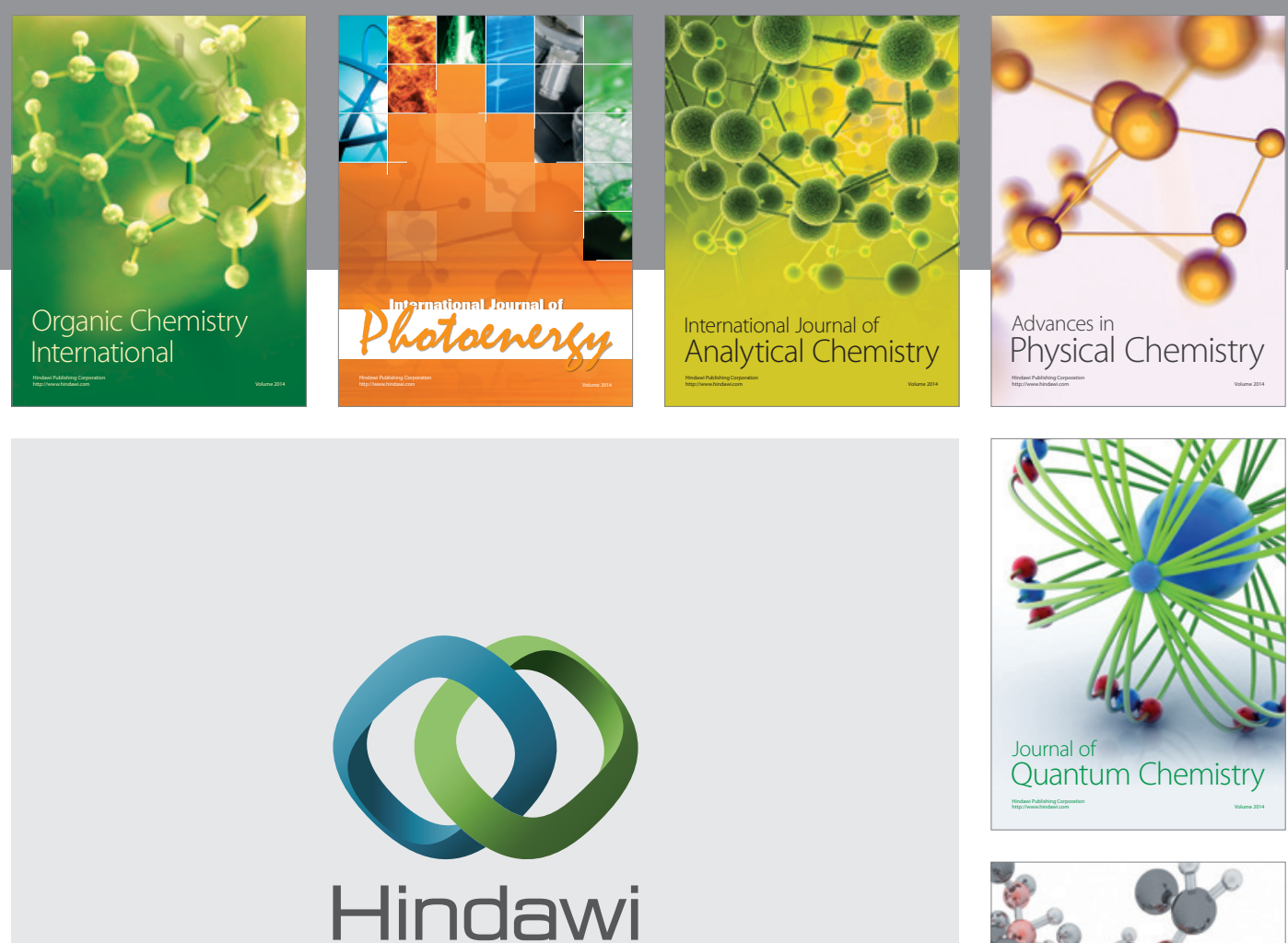

Submit your manuscripts at

http://www.hindawi.com

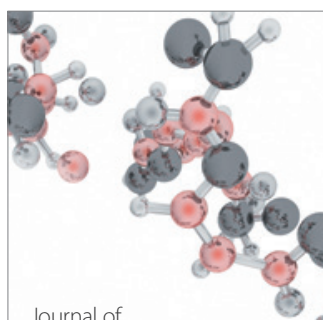

Analytical Methods

in Chemistry

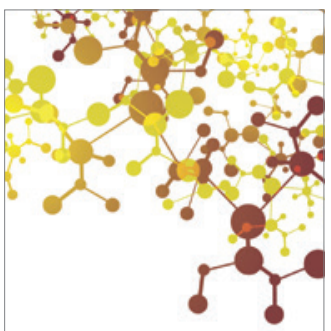

Journal of

Applied Chemistry

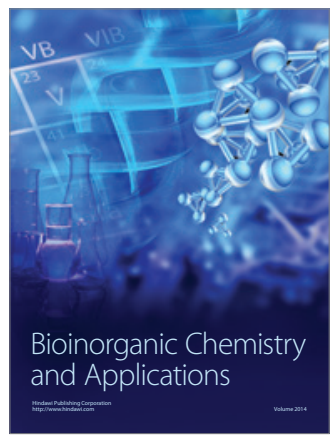

Inorganic Chemistry
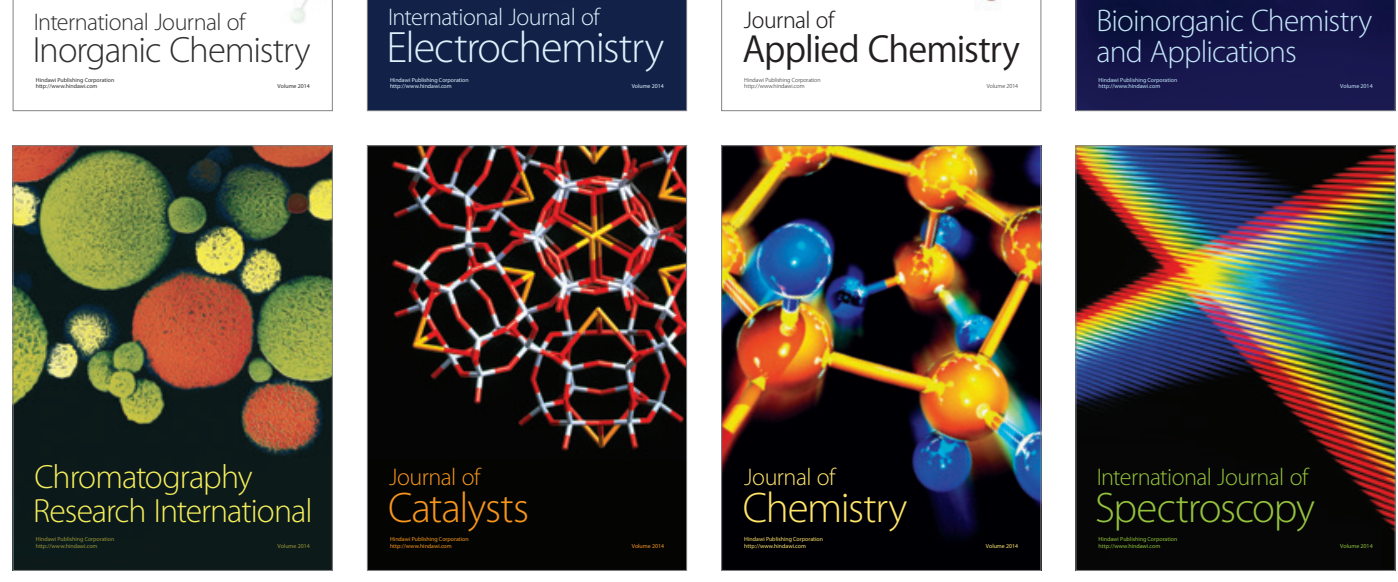